\title{
Research Square \\ Proposal for name of surgical access-Substernal instead Subxiphoid for pericardial fenestration
}

Daniel Georgiev Valchev ( $\nabla$ dg_valchev@abv.bg )

Research note

Keywords: pericardial tamponade; subxiphoid; substernal

Posted Date: September 12th, 2019

DOI: https://doi.org/10.21203/rs.2.14397/v1

License: (c) (i) This work is licensed under a Creative Commons Attribution 4.0 International License.

Read Full License 


\section{Abstract}

Objective: Various surgical accesses for pericardial fenestration are described and used in the literature. Each of them has its advantages and disadvantages depending on the cause of the need for pericardial fenestration. Results: Operative and perioperative mortality has not been reported. Operative complications such as bleeding, injury to the coronary artery or myocardium have not occurred. Substernal access after resection of the xiphoid process is a safe and effective approach for surgical treatment of pericardial tamponade.

\section{Introduction}

Pericardial fenestration is a surgical procedure which is performed to remove pericardial fluid from the pericardial cavity. In cases of cardiac tamponade, the methods used to reach the pericardium rapidly and ensure recovery, are suitable for performing under local anesthesia and sedation.

\section{Methods}

From 2000 to 2017 in the Clinic of Thoracic Surgery of University Hospital, St. Zagora, forty two patients were diagnosed with Pericardial tamponade and then operated. The men were 26 at the average age of 33 in the range of 19 to 82 . The women were 16 at the average age of 59 years in the range of 20 to 73. The VATS - Fenestratio pericardii procedure was received by eight patients. In the remaining 34 patients, a substernal pericardial fenestration was performed after resection of the xiphoid process under local anesthesia and sedation.

Surgical technique: Small longitudinal incision of 5-7 cm along the midline is done starting $1 \mathrm{~cm}$ above the top end of the xiophoid process and ending $1 \mathrm{~cm}$ below its lower part. The skin and the subcutaneous tissue is cut off by introducing the process. Above the top (the lower end of the xyphoid process) appears the linea alba. With Kocher's clap, the tip picks up and pulls forwards and upwards, then with the help of electronic knife it is totally expanded (front and rear) to the base (xiphosternal joint). Then the resection of the xiophoid follows with bone scissors. With a retractor, the lower part of the sternum is lifted, and with a gauze swab it is pressed and taken down the preperitoneal adipose tissue at the lower end of the incision. After the resection, it is penetrated in depth up, back and left in the lean fat of the lower anterior medastinum, and the pericardium is reached in front of the right ventricle. On the way, the surgeon does not encounter any large vessels or other important anatomical elements that slow him down and make his access to the pericardium difficult. Objectively, in the advanced technique, at first, resection of the xiophoid process is performed and then substernal penetration. Substernal access probes show that after resection and removing of the xiophoid process, the surgeon gets enough broad and comfortable space to work with the front and right side of the pericardium in front of the right ventricle.

\section{Results}


By 34 patients with a pericardial tamponade, a substernal access was used after resection of the xiophoid process. Operative and perioperative mortality has not been reported. Operative complications such as bleeding, injury to the coronary artery or myocardium have not occurred. Average operating time is $38 \mathrm{~min}$ and average duration of hospital stay is 5 days. The average duration of the pericardial and mediastinal catheter stay is 4 days.

\section{Discussion}

The method of subxyphoid pericardial fenestration was described by Larrey DJ in 1829. (1) Later in 1900, Ogle and Allingham began to popularize the procedure. (2) Fontenelle et al. In 1970 began the use of the current technique of subxyphoid access (after resection and removal of the xiophoid) to open a pericardial window. (3) Since then, in many authors' work, this method remained one of the main techniques for pericardial fenestration. The only change over the years is the resection and removal of the

xyphoid process to facilitate access. $(4,5)$ Initially, in the operative protocols the procedure was registered in the same way as it is commonly accepted in the global cardio-thoracic community as a subxiphoid pericardial window. In the interest of accuracy and surgical clarity after resection and removal of the xiophoid process, the attitude to the anterior lower mediastinum and the pericardium is substernal. The author's view is that changing the name of the access will not downplay and change the dignity and uniqueness of the method described 190 years ago and used to date by Larrey.

The use of subxiphoid operative access for pericardial fenestration 190 years after its first description by Larrey DJ in 1829 shows its uniqueness and applicability, especially in the case of pericardial tamponade. After the resection and removal of the xiphoid process, the surgeon receives a sufficiently wide and comfortable working space. Substernal access after resection of the xiphoid process is a safe and effective approach to surgical treatment of pericardial tamponade.

\section{Limitations}

This research article covers data from only 34 patients. This suggests broadening the scope of research in future. It should be also noted that the surgical approach in question is proposed only in patients with cardiac tamponade.

\section{Abbreviations}

VATS - Video-Assisted Thoracic Surgery

\section{Declarations}

\section{Ethics Approval and Consent to Participate:}

All procedures performed in this study involving human participants were in accordance with the ethical standards of the institutional and/or national research committee (Committee for Ethics of University Hospital Prof. Dr. St. Kirkovich with a chairman dr. Valcova, Stara Zagora, Bulgaria) and with the 1964 
Helsinki declaration and its later amendments or comparable ethical standards. All participants in the study have signed an informed consent form.

\section{Availability of data and materials:}

All data generated or analysed during this study are included in this published article [and its supplementary information files].

\section{Funding:}

This research is self-funded and the author does not recieve any funds for his work on this research.

\section{Competing interests:}

None declared.

\section{Consent to publish:}

Not applicable

\section{Authors' contributions:}

only one author - not applicable

\section{Acknowledgements:}

not applicable

\section{References}

1. Larrey DJ. New surgical procedure to open the pericardium and determine the cause of fluid in its cavity. ClinChir 1829;36:303.

2. Ogle $\mathrm{C}$, Allingham $\mathrm{H}$. A suggestion for a method of opening the pericardial sac, founded upon a case of purulent pericarditis. Lancet 1900;155:693-695.

3. Fontenelle LJ, Cuello L, Dooley BN. Subxiphoid pericardial window. AmJ Surg 1970;120:679-680.

4. Moores DW, Allen KB, Faber LP, Dziuban SW, Gillman DJ, Warren WH, et al.Subxiphoid pericardial drainage for pericardial tamponade.J Thorac Cardiovasc Surg. 1995 Mar;109(3):546-51;discussion 551-2.DOI: 10.1016/S0022-5223(95)70287-3

5. Gil H. Santos, Gil H. Santos, R.W.M. Frater. The Subxiphoid Approach in the Treatment of Pericardial Effusion; The Annals of Thoracic Surgery Volume 23, Issue 5, May 1977, Pages 467-470 DOI: https://doi.org/10.1016/S0003-4975(10)64168-9 